\title{
O consentimento informado. Qual o seu real valor na prática médica?
}

\section{Informed consent: what is it real value in medical practice?}

José Guilherme MinossI, TCBC-SP1

\author{
R E S U M O
}

Trata-se de um artigo que comenta sobre a real importância do Termo de Consentimento Informado na prática médica. Este documento tem sido cada vez mais usado como uma prática defensiva, a fim de constituir provas para defesa de um eventual processo judicial de responsabilidade médica, desvirtuando assim a idéia original, que seria a de respeitar a autonomia do paciente e delimitar a responsabilidade médica. O documento tem como objetivo mostrar que o médico cumpriu com seu dever de informar. Seu grande valor reside nos casos onde existam riscos de danos irreversíveis ao paciente. Conclui-se, porém, que um prontuário bem elaborado onde se inclui o registro das informações que foram transmitidas, bem como o grau de participação dos pacientes e seus familiares nas decisões terapêuticas, também deve ter valor ético e jurídico semelhante do $\mathrm{TCl}$.

Descritores: Termos de consentimento. Responsabilidade legal. Ética médica. Medicina geral.

\section{HISTÓRICO}

O primeiro registro científico de que se tem notícia sobre o uso de um documento para se estabelecer uma relação entre o pesquisador e o indivíduo pesquisado data de 19 de outubro de 1833. O pesquisador era o médico William Beaumont (1785 - 1853), considerado o primeiro fisiologista norte-americano e o fundador da Gastroenterologia, e o sujeito da pesquisa, Alexis St. Martin. Este paciente tinha uma seqüela de um tiro por arma de fogo no abdome, a qual permitia a observação do interior do seu estômago; problema que o acompanharia por anos a fio.

No documento firmado entre William Beaumont e seu paciente, este receberia, além de casa e comida, a quantia de $U \$ 150.00$ para que ficasse disponível para todos os experimentos que fossem realizados, durante o período de um ano. Esta relação, embora inusitada e criticável sob o ponto de vista ético, tem sido considerada a precursora do Termo de Consentimento Informado (TCI).

Embora houvesse uma autorização entre o pesquisador e o pesquisado, os demais critérios necessários para que se obtivesse um consentimento informado aparentemente não estavam contemplados, como a voluntariedade da ação, as informações que lhe foram transmitidas e sua compreensão sobre as mesmas.

No de 1983, Beaumont também estabeleceu o primeiro código de Ética na Pesquisa de que se tem co- nhecimento. Eram diretrizes para a experimentação responsável. Uma dessas diretrizes estabelecia que era necessário o consentimento voluntário dos indivíduos participantes. Uma outra proposta estabelecia que o projeto deveria ser abandonado caso o participante assim o desejasse ${ }^{1}$.

Apesar deste marco histórico, durante décadas não houve por parte dos pesquisadores o devido respeito à voluntariedade e autonomia dos pesquisados, até que surgiu o primeiro Código Internacional de Ética para pesquisas envolvendo seres humanos - o Código de Nuremberg, que foi uma resposta às atrocidades cometidas por médicos pesquisadores nazistas, que acabaram por ser reveladas nos julgamentos de crimes de guerra.

Assim, a ética da pesquisa em seres humanos surgiu para impedir que tais atos viessem a se repetir. $O$ Código de Nuremberg, publicado em 1947, estabeleceu os padrões para a realização de experiências com seres humanos, enfatizando o consentimento voluntário do participante ${ }^{2}$.

A normatização do uso do Termo de Consentimento Informado (TCl) no Brasil se iniciou na década de 80. Dois documentos, um do Ministério da Saúde e outro do Conselho Federal de Medicina, estabeleceram as bases para o uso deste documento, respectivamente, em pesquisa e assistência (Conselho Federal de Medicina. Resolução 1081, de 12 de março de 1982. Ministério da Saúde. Portaria16, de 27 de novembro de 1981).

Trabalho realizado no Departamento de Cirurgia e Ortopedia da Faculdade de Medicina de Botucatu - Unesp- SP-BR.

1. Professor Assistente e Doutor do Departamento de Cirurgia e Ortopedia da Faculdade de Medicina de Botucatu - Unesp - SP-BR. 


\section{CONSIDERACCÕES SOBRE O TERMO DE CONSENTIMENTO INFORMADO}

Trata-se de documento assinado pelo paciente ou responsável, consentindo ao médico a realização de determinado procedimento diagnóstico ou terapêutico, após haver recebido informações indispensáveis sobre a sua execução. Tem como finalidade garantir a autonomia de vontade do paciente e delimitar a responsabilidade do médico que realiza o procedimento, cumprindo desta forma, o seu dever de bem informar.

O consentimento deve ser obtido de um indivíduo civilmente capaz, isento de coação, influência ou indução, por meio de linguagem acessível ao seu nível de conhecimento e compreensão. O consentimento não é um ato irretratável e permanente, portanto, deve obedecer princípios da revogabilidade e da temporalidade ${ }^{3}$.

Este documento passou a ser utilizado com maior freqüência a partir de 1970, quando houve uma importante transformação cultural no padrão de atendimento à saúde ${ }^{4}$.

Durante séculos, a relação médico-paciente seguiu os pressupostos da deontologia hipocratica sem grandes perturbações. Porém, esta doutrina alijava o paciente das decisões sobre o seu próprio corpo, deixando o médico livre para agir supostamente em seu benefício.

A grande mudança cultural ocorrida nas últimas décadas, no entanto, e os enormes avanços tecnológicos da Medicina, que em muito beneficiou o ser humano, tornou esta ciência mais invasiva, portanto, sujeita a maiores riscos. Neste contexto, fez-se necessária uma maior participação dos pacientes nas decisões a serem tomadas com relação aos procedimentos diagnósticos e terapêuticos.

Segundo entendimento do Conselho Federal de Medicina, o TCl deve conter:

Identificação do paciente ou de seu responsável;

Nome do procedimento;

Descrição técnica (em termos leigos e claros);

Possíveis insucessos;

Complicações pré, per e pós procedimento;

Descrição do procedimento anestésico (caso necessário);

Explicação quanto à possibilidade de modificação de conduta durante o procedimento;

Declaração de que as explicações foram efetivamente entendidas;

Confirmação de autorização, com local e data da realização do procedimento;

Modelo para revogação do procedimento;

Assinatura de testemunhas.

O conjunto de informações a ser transmitido ao paciente, seja através de comunicação oral ou através do $\mathrm{TCl}$ deve satisfazer às expectativas de todos os pacientes, considerando as respectivas condições sócio-econômicoculturais, não havendo necessidade que as mesmas sejam tecnicamente detalhadas e minuciosas, e sim, que sejam corretas, honestas e compreensíveis.

O TCI não deve conter termos estritamente técnicos sobre o procedimento a ser realizado, pois dificulta a compreensão do paciente, devendo, pois, tal linguagem técnica ser adaptada de maneira a permitir fácil compreensão pelo leigo, evitando assim futuros questionamentos sobre sua validade (vícios de consentimento). Esses vícios de consentimento fazem com que, frequentemente, este documento seja rejeitado pelo juiz, por ocasião de um conflito médico-legal.

O TCI não é irretratável, sendo assegurado ao paciente o direito de revogá-lo a qualquer momento, sem que isso gere consequências éticas ou jurídicas, salvo em situações de emergências médicas, onde a manutenção da vida é o maior propósito do médico. Nestes casos, o documento pode ser dispensado.

Importante ressaltar que este documento apenas respalda ao médico, que o mesmo cumpriu o seu dever de bem informar, que é um dos seus deveres de conduta. Assim, sua existência não significa que o profissional médico estará isento de possíveis questionamentos sobre sua responsabilidade, sobre eventuais erros ou falhas advindas do procedimento realizado, ainda que este tenha sido consentido.

Atualmente, aceita-se a existência de, pelo menos, duas distintas concepções sobre o consentimento informado ${ }^{4}$. Em uma delas, que tem a Medicina defensiva como referencial, se entende que o $\mathrm{TCl}$ é um instrumento documental, que deve ser assinado pelo paciente, e que tem como objetivo constituir provas para a futura defesa de um eventual processo judicial de responsabilidade médica. Já na outra, fundada na Bioética, concebe-se o consentimento informado como um processo continuado de informação e esclarecimento recíproco, nas relações entre prestadores e usuários de serviços de saúde, visando a proteger prioritariamente a autodeterminação do paciente.

O TCI não deveria ser utilizado como um instrumento defensivo, pois a Medicina defensiva é considerada por muitos como um desvio da prática médica sensata, induzida, principalmente, pela ameaça de processos por negligência profissional. Além de ineficiente em proteger o médico, ela traz conseqüências graves ao paciente e à sociedade, já que gera um custo adicional incalculável ao exercício da Medicina, uma vez que determina maior sofrimento ao doente, levando à quebra da relação médicopaciente, que foi sempre pautada pela confiança, respeito e pessoalidade.

Portanto, este documento deveria ter como objetivo garantir a autonomia de vontade do paciente e delimitar a responsabilidade do médico que realiza o procedimento (dever de informação) ${ }^{5}$.

Um paciente, por exemplo, que por motivos religiosos, não aceita a transfusão de sangue durante uma operação, tem sua vontade e autonomia expressa neste documento, e o médico sua responsabilidade delimitada. Isto certamente, evitaria os confrontos entre médicos e 
pacientes que por não aceitarem a transfusão sanguínea, são com freqüência discriminados e recusados em atendimento médico invasivo.

Outra situação em que se faz necessária o uso do $\mathrm{TCl}$ é aquela em que o doente vai sofrer um procedimento invasivo, com risco grande de seqüelas ou mutilações ou mesmo desconforto e sofrimento ${ }^{6}$. Por exemplo, um paciente que será submetido a uma operação neurológica com grande risco de seqüela. Um TCl obtido após amplo esclarecimento verbal, é importante para trazer alguma proteção ao profissional que executa o procedimento.

Da mesma maneira, um paciente que será submetido ao tratamento cirúrgico de uma hérnia, deverá ser orientado quanto às possibilidades da recidiva e de eventuais complicações tardias do uso das próteses ${ }^{7}$.

Entendemos que se essas informações forem adequadamente registradas em prontuário, terão valor ético e legal semelhante ao Termo de Consentimento. Isto porque o TCI não consegue prever todas as possibilidades de intercorrências ou complicações em um determinado caso.

$\mathrm{O} \mathrm{TCI}$ não deve ser usado como substitutivo da comunicação oral, podendo assim, ao contrário de seu objetivo, gerar desconfiança em relação aos médicos e aumentar a potencialidade de conflitos. A informação escrita pode ajudar o diálogo, mas não o substitui.

Sendo assim, embora o consentimento informado seja uma exigência ética e jurídica na assistência médica atual, entende-se que não é necessário e nem aconselhável se obter a assinatura do paciente em todo e qualquer procedimento, numa clara prática de Medicina defensiva. Não há garantia de que esta conduta irá evitar futuras demandas judiciais, além de, com isso, criar-se um distanciamento e desconfiança na relação médico-paciente.

Da mesma forma, deve-se evitar exageros na elaboração do documento, uma vez que tal prática pode assustar o paciente e dificultar seu acesso ao tratamento. Se a um jovem que vai ser submetido a uma herniorrafia inguinal, o fizermos assinar que após o procedimento, o mesmo poderá perder um testículo, certamente irá se recusar a submeter-se ao tratamento cirúrgico, podendo vir a ter as complicações de sua doença posteriormente.

Porém, é recomendável que os médicos mantenham sempre os prontuários dos pacientes adequadamente elaborados, incluindo o registro das informações que foram transmitidas e o grau de participação dos pacientes e seus familiares nas decisões terapêuticas. Tais documen- tos, caso sejam devidamente preenchidos, podem servir como prova de que foi cumprido o dever de informar, que é o conteúdo do consentimento informado. As anotações no prontuário também servem para registrar o grau de comprometimento e cooperação dos pacientes, o que é imprescindível para a eficácia dos serviços médicos.

\section{CONSIDERAÇÕES FINAIS}

Não há dúvidas de que o TCl cada vez mais vem sendo usado no nosso meio, como uma prática defensiva, a fim de constituir provas para defesa de um eventual processo judicial de responsabilidade médica. Desse modo, há um desvirtuamento da idéia original de consentimento informado, que seria a manutenção de uma aliança terapêutica produtiva e de confiança, entre o médico e o paciente.

Essa exigência indiscriminada da expressão escrita do consentimento, com priorização da assinatura do paciente, em detrimento de um real processo de comunicação, pode redundar em uma ruptura nas relações médico-paciente, gerando um mal-estar na prestação assistencial e também nas participações em pesquisas.

Em nosso entendimento, o grande valor deste documento se refere aos casos onde existam riscos de danos irreversíveis aos pacientes.

$\mathrm{O} \mathrm{TCl}$ tem como maior objetivo mostrar que o médico cumpriu com seu dever de informar.

Certamente, um prontuário bem elaborado, onde se incluiu o registro das informações que foram transmitidas, bem como o grau de participação dos pacientes e seus familiares nas decisões terapêuticas, deve ter valor ético e jurídico semelhante ao TCI.

O profissional tem que entender que o ato médico mesmo que bem intencionado e corretamente realizado, continuará regido pelas regras de responsabilidade civil, ética ou penal. O médico deve ter em mente que a melhor maneira de se proteger de eventuais condenações é conhecer profundamente seus deveres de conduta, atuando com o maior zelo e carinho no exercício profissional, evitando assim a produção de um dano decorrente de um ato culposo.

\section{Agradecimento}

Os autores agradecem aos professores William Saad Hossne e César Tadeu Spadella pela revisão do texo e valiosas sugestões.

\section{A}

This is an article that talks about the real importance of Informed Consent (IC) in medical practice. This document has been increasingly used as a defensive practice, in order to provide evidence to the defense of any lawsuit of medical responsibility, thus distorting the original idea, which would be to respect patient autonomy and delimit medical liability. The document aims to show that the doctor complied with his duty to inform. Its great value lies in cases where there is a risk of irreversible damage to the patient. We conclude, however, that a well-documented chart, which includes the recording of information that was provided and the degree of participation of patients and their families in treatment decisions, should also have legal and ethical value similar to the IC's.

Key words: Consent forms. Liability, legal. Ethics, medical. General practice. 


\section{REFERÊNCIAS}

1. Kapp MB. A history and theory of informed consent. J Leg Med 1986; 7(3):397-402

2. Giostri HT. Sobre o consentimento informado: sua história, seu valor. J Vas Br 2003; 2(3):267-70.

3. Minossi JG. Prevenção de conflitos médico-legais no exercício da medicina. Rev Col Bras Cir 2009; 36(1):90-5.

4. Pithan LH. O consentimento informado para além da medicina defensiva. AMRIGS 2009; 53(2):175-8.

5. França GV. Direito médico. 8a ed. São Paulo: BYK; 2003. Responsabilidade médica; p.189-237.

6. Bonamigo EL. O valor do consentimento informado. AMRIGS 2008; 52(4):330-3.

7. Minossi JG, Silva AL, Spadella CT. O uso da prótese na correção das hérnias da parede abdominal é um avanço, mas o seu uso indiscriminado, um abuso. Rev Col Bras Cir 2008; 35(6):418-24.
Recebido em 11/10/2010

Aceito para publicação em 16/11/2010

Conflito de interesse: nenhum

Fonte de financiamento: nenhuma

\section{Como citar este artigo:}

Minossi JG. O consentimento informado. Qual o seu real valor na prática médica ?. Rev Col Bras Cir. [periódico na Internet] 2011; 38(3).

Disponível em URL: http://www.scielo.br/rcbc

\section{Endereço para correspondência:}

José Guilherme Minossi

E-mail:jminossi@uol.com.br jminossi@fmb.unesp.br 